\section{Using Open Journal Systems to Move from Paper Production to Online Open Access}

\author{
Laura C. Botsford \& Kevin D. Haggerty \\ University of Alberta
}

Scholarly and Research

Communication

VOLUME 1 / ISSUE 1 / 2010

\begin{abstract}
The Canadian Journal of Sociology (CJS) is an independent, peer-reviewed publication, originally constituted as a charitable organization in 1975 . From 1975 to 2008 , the CJS was printed quarterly and mailed to its subscribers. The move to open access and Open Journal Systems in 2008 has meant some philosophical and pragmatic adjustments. In outlining these adjustments, the authors hope to guide other journals that may be contemplating the same move. Although they focus their comments on the use of Open Journal Systems' open source software, they are easily transferrable to other programs and situations.
\end{abstract}

\section{Keywords}

Open Journal Systems; Open access publishing; Scholarly journals; Open source software
Laura C. Botsford is Assistant to the Editor, Canadian Journal of Sociology, Department of Sociology, University of Alberta, Edmonton, AB T6 $6 \mathrm{G}_{2} \mathrm{H}_{4}$. Email: botsford@ualberta.ca. Kevin D. Haggerty is Professor in the Department of Sociology, University of Alberta, and Editor of the Canadian Journal of Sociology. Email: kevin.haggerty@ualberta.ca.

CCSP Press

Scholarly and Research Communication

Volume 1, Issue 1, Article ID o10301, 12 pages

Journal URL: www.src-online.ca

Received September 3, 2009, Accepted October 16, 2009, Published January 1, 2010

Botsford, Laura C., \& Haggerty, Kevin D. (2010). Using Open Journal Systems to Move from Paper Production to Online Open Access. Scholarly and Research Communication, 1(1): 010301, 12 pp.

(c) 2010 Laura C. Botsford, Kevin D. Haggerty. This Open Access article is distributed under the terms of the Creative Commons Attribution Non-Commercial License (http://creativecommons.org/licenses/bync-nd $/ 2.5 / \mathrm{ca}$ ), which permits unrestricted non-commercial use, distribution, and reproduction in any medium, provided the original work is properly cited. 
Scholarly and Research

\section{Communication}

VOLUME 1 / ISSUE 1 / 2010

\section{Introduction}

As a generalist sociology journal, the Canadian Journal of Sociology (CJS) receives and publishes a wide range of peer-reviewed submissions written by both Canadians and international authors - articles that range from the theoretical to the statistical, quantitative and qualitative, and on topics of interest to, or having an affect on, Canadian life. The journal also publishes review essays, book reviews, notes on society, and notes on the discipline, the latter two of which are not peer reviewed but provide a venue for shorter, more topical commentaries. In our previous incarnation as a print journal, we received funds from subscriptions, reprint fees, and the Social Sciences and Humanities Research Council (SSHRC). ${ }^{1}$ As an open access, online journal, the majority of our funding now comes from a competitive grant from the SSHRC.

The CJS has always been housed at the University of Alberta and until January 2007 was edited by Professor Nico Stehr. The advent of the Internet and, particularly, desktop computers allowed Professor Stehr - with a half-time editorial assistant ${ }^{2}$ - to actively encourage new initiatives during his extended term as editor. In 2007, he stepped down and handed the editorship to Kevin Haggerty. It fell to Kevin to make the decision to move from print to online publishing, the most momentous step taken in the history of the CJS.

In this article, we outline some of the pros and cons of moving from a paper, subscription-based publishing model to an online, open access format. The article is a joint initiative by Laura Botsford, current Assistant to the Editor, and Kevin. However, as the discussion concentrates on changes in day-to-day practices that often fall to Laura, she is identified throughout the paper in the first person.

When Kevin and I began moving the CJS online, many of its content management systems (CMS) were still primarily paper-based. The University of Toronto Press had managed the actual production of the journal since 1990. Once manuscripts were accepted and a final copy received, they were sent to the University of Toronto Press, where they were typeset (from electronic files produced by the CJS) and printed. The press was also responsible for tracking and maintaining subscriptions. By the time Kevin and I were considering moving to online publication the costs of print publication made it an unsatisfactory option.

As Kevin considered various options, it became clear that we were contemplating three major areas of change, all of which could be achieved using Open Journal Systems (OJS). OJS is open source software produced and serviced by the Public Knowledge Project, a partnership among the Faculty of Education at the University of British Columbia, the Simon Fraser University Library, the School of Education at Stanford University, and the Canadian Centre for Studies in Publishing at Simon Fraser University.

The first change involved our CMS. The second change was in our distribution medium: from paper publishing, available only by subscription and mail, to Web-based publishing. The third change involved a new distribution model to support open access (OA) publishing, making the CJS available without charge to anyone in the world with 
an Internet connection. These three changes were interrelated, but the move to an OA business model was the one that kept Kevin awake at night. The first two, since I would be the one implementing them, were the ones that made me particularly nervous.

\section{Changing the CMS}

Established journals have developed various systems of record-keeping for subscriptions, reviewers, advertisements, revenues, et cetera. Much of this information is required by SSHRC when submitting a funding application. All of it is potentially useful to an editor, particularly for journals where the editorship changes on a regular basis. Even if the records are computerized - as most are these days - the programs used to maintain them, and the rubric used to organize them, often differ from editor to editor and even institution-to-institution. However it happens, reviews have to be tracked, reviewers prompted and thanked, and authors notified of decisions.

If the editor maintains the journal alone, or with the help of a graduate student or parttime employee (the CJS model), then accessing information is reasonably easy.

If, however, a journal is large enough to have an editor, a full-time copy editor, a subscription manager, and an office assistant, things become more complicated. Records are unlikely to be accumulated on only one or even two computers; overlapping responsibilities (and there is always overlap in responsibilities) means constantly having to interrupt one's workflow to get information from somewhere else. Different people and areas will have their information organized in different ways, making access more difficult and often time-consuming.

At the CJS, manuscripts had long been tracked, and reviewers assigned, using an index card system. Reviews were requested and received by email. Many, but by no means all, manuscripts were also received by email; the rest appeared in paper form accompanied by an electronic form on diskette or CD. The diskettes were usually, but not always, Windows-based. Paper files were maintained for all manuscripts, requiring an ever-expanding amount of storage space. From the index files, the previous editorial assistant had generated various computerized tracking files, but there was not much consistency among them. All records were on her Windows-based computer; to access them or the index cards, one had to visit her office.

Professor Stehr managed the CJS from off campus for the last several years of his editorship, and this model suited him well. Kevin, however, is based at the University of Alberta and wanted direct access to the CJS records, whether he was working offcampus, attending conferences, or working on campus. An online CMS therefore made a lot of sense, and Open Journal Systems looked like an excellent option. As it turned out, both Kevin and I are Macintosh enthusiasts, and the CJS equipment was updated to reflect that, but doing so was not required to adopt OJS.

A second, significant advantage to OJS was that it is actively supported by the University of Alberta library system. This means that we can obtain technical assistance with problems as they arise, whether they are solved at the University of Alberta or have to be referred to the OJS forums. Knowing that assistance was as close as a phone call or email was reassuring, rather like seeing a lovely, thick mattress at the bottom of the cliff we were about to jump off.
VOLUME 1 / ISSUE 1 / 2010 
Scholarly and Research Communication

VOLUME 1 / ISSUE 1 / 2010
Once we were committed to OJS, the magnitude of the change loomed large. The reviewer database had to be entered into the system. An HTML style sheet had to be put together to provide our home page with its own "look and feel." Papers that would be part of the inaugural online issue had to be entered into the system. Manuscript rating forms had to be developed, emails personalized, and so on. An automatic system, it turns out, is only as good as the data fed into it. In the months following the changeover, I spent a lot of time searching for reviewers, entering their details into the system, and asking them to review manuscripts.

OJS supports either the model of many people for many jobs or one person for many jobs. Keeping the records in one place - online - means that everyone always has computer access and the organization is uniform. The interface is the same for all users, wherever they are. Everyone must therefore adapt to the software program's logic - a logic that is not always intuitively obvious - but once it is understood, the program can be relied on to produce consistent results.

OJS incorporates several different roles, the major ones being as follows:

Journal Manager. People with this role can add and delete users, add roles, log on as other users, and edit or change all the underlying information and functions within the journal. They do not, however, have direct access to articles or any of the publishing steps.

Editor. The people or person with this role can see all the papers under review, whether assigned to them, or not. They are responsible for assigning reviewers and can track the progress of reviews, submit their decision, and track the paper through the publication process. Editors assign the articles to issues and set up future issues as needed. There can be several section editors (one for book reviews, one for articles, one for copyediting, et cetera) or only one person who performs all of these functions.

Reviewer. People who are listed as "reviewer" can review papers that are assigned to them by the editor. They only have access to the paper or papers they have been asked to review. The review process is managed online; in those cases where a reviewer is uncomfortable with the computer process or has browser/system/institution issues with accessing the reviewer page, the review can still be submitted by email. In such cases, the review must be added to the system by the Journal Manager.

Author. These individuals can submit papers for review. They can also track information on the paper's status online (in review, decision pending, et cetera), but do not have access to any other journal functions. At this point, however, status tracking is in broad strokes, rather than minute detail. You can expect authors to query the meaning of "queued for review" if the process is prolonged.

Reader. Readers have access to the issues posted online and can receive automatic notices when new issues are published. Access can be set on a subscription model or open access. Since we opted for open access at the CJS, that is the model we discuss here.

As noted, each of these roles can be held by one person or by many people. The OJS set-up assumes many people, each with one function, and each needing to access that 
function, whether someone else is using the system or not. For the CJS, and journals like it, this means that roles must constantly be changed according to the particular job at hand. Because each role must be accessed consecutively (i.e., one cannot be logged on as both Editor and Journal Manager simultaneously), the simple process of adding a review for a reviewer can necessitate changing roles several times. For instance, in the event that an author wishes to submit a paper but is unable or unwilling to do so directly through OJS, this is the current sequence of events:

I must log into the system. As the Journal Manager, I must create an ID for the author, entering as much of the relevant metadata for author and article as I can. To do this, I execute the following steps:

- Click on the "Journal Manager" role and wait for that role to load.

- Click on "Users enrolled in this journal" and wait for that page to load.

- Search for the author's name in the system, as an author may have reviewed a paper for us in the past or be enrolled as a reader. The system does not allow duplications, so it pays to check here first. Type author's name, click search, wait.

- Assuming the author's name is not in the database, click on "Create New User" and wait for that page to load.

- Enter the author's information, creating a password, giving him/her the roles of author, reviewer, reader (this saves time in case you want him/her to review a paper for the journal later). The system will create a random password if you ask it to, but we have found that enough people lose their passwords that having one we can give them on request works best. Type, type, type, click on save, wait to be returned to the main Journal Manager page.

- Search for the author. Click, wait for his name to load.

- Log in as the author and go through the submission process. Click, wait. Click, wait. Type, type, type, click, wait. Click, wait for the article to be uploaded.

Click, wait, click wait.

- Now I can log out as the author. Click. Wait to be returned to the main Journal Manager page.

Depending on my Internet access (and being able to do this entire process anywhere I have Internet access and a computer is a huge advantage - although not all Internet access is created equal), this process may have taken me half an hour. I still have not assigned an editor or reviewers, all of which can only be done under the Editor role. So...

- Click on "User Home," wait for that page to load.

- Click on "Editor," wait for that page to load.

- Click on "Unassigned," wait for that page to load.

And so it goes.

Assigning reviewers is one area where OJS has recently improved. Moving from the roles of Editor to Journal Manager to assign reviewers is now seamless, even if the
VOLUME 1 / ISSUE 1 / 2010 


\section{Scholarly and Research} Communication

VOLUME 1 / ISSUE 1 / 2010 reviewer you want to assign is not in the system. Once the reviewer is located and assigned, you are automatically taken back to the Review page of the paper, where you can assign as many other reviewers as you think you will need.

For the CJS in its new online incarnation using the OJS system, both Kevin and I function as Journal Manager, Editor, Section Editor, Copy Editor, Author, and Reviewer. We do not use the last two now, but had to learn how they worked in order to provide guidance to others. Although the OJS has an impressive system for backing up files at multiple sites, as an extra precaution I keep separate computer database records of much of the information in OJS about the status of manuscripts. Thirty years of working with computers has taught me the value of the "belt and suspenders" approach to keeping information safe.

\section{Changing the distribution model}

For the first 20 years of its existence, the CJS was produced in-house, eventually using an off-campus printer to produce the final, printed and bound copies. Needless to say, at first everything happened on paper, and as computers became more common, reliable, and affordable, tasks such as copy-editing happened on paper and on the computer. Typesetting moved from text markup for a mainframe ${ }^{3}$ to desktop publication using PageMaker and then InDesign. The final versions were exported as PDF files and sent to the printer. Subscriptions also were formerly managed in-house. I mailed out the subscription copies - a process that involved sorting by postal code, bundling, counting, and delivering to the post office. It took most of a day and the use of the Sociology Department's conference room.

When the print production moved to the University of Toronto Press this distribution process changed. Once the paper copies of an issue were sent off to the editors at $U$ of T Press, it was out of our hands. They did some minor copy-editing, the typesetting, the printing, and management of the subscriptions. The system worked well for several years, but by the time Kevin took over as editor of the CJS, we were ready to move things in-house again.

Moving to an online model using Open Journal Systems made a lot of sense to us. The software is robust, with all the elements of communication and tracking built in. We could use the program's functionality as much or as little as we wished. We could, for instance, have opted to publish each issue online, while continuing to track reviewers and manuscript status by email and index cards. Since part of the appeal of OJS for both Kevin and myself was the ability to access and update information from anywhere, we opted to adopt almost the entire package. And then the fun began!

An early question we had to address concerned our online user interface. OJS ships with a number of canned templates, which are handy for a new journal. As an established journal, we wanted to maintain "brand awareness," so Kevin hired a Web designer to write a style sheet for the CJS. This can, of course, be done in-house, but it requires a knowledge of HTML coding that neither Kevin nor I possess. Some of the glitches in this style sheet became clear very quickly, and some we are still discovering. It turns out that background color and text colour can combine in unexpected and undesirable ways onscreen. Not until I watched our library resource person click on the 
journal's banner did I realize that each paper had several helpful categories, including: Summary, which stores the paper's metadata; Review, which tracks the reviewer information; Editing, which tracks the paper through production; and History, which stores all the actions and emails related to that paper. The background colour was dark grey and the type for the headings was black. Not as readable as one might wish.

As I learn more about OJS' functionality, I am discovering more problematic areas. Again, thanks to our library resource person, I discovered that OJS has Reading Tools, which, when you do not have a dark background and black type, show up beside the PDF of a published article. We are still trying to work out where in our customized style sheet the background and type combination can be changed. Deciding to use OJS to send out galleys, I discovered that the proofing instructions were also black-on-black.

After designing an online interface came the tedious work of re-entering database information (a process that provided ample familiarity with the Journal Manager role). With that done, it was time to play with the system, find out how it works, develop a familiarity with its logic (which was not always our logic). It is very helpful to have someone else discovering the system at the same time. While Kevin started the process of learning the system - a necessary step in making the decision to adopt it - I have since learned a great deal more about how it works. Different people approach a problem in different ways, and we have been able to help each other on several occasions.

Computer access is never as simple as it looks. A surprising number of people use computers as a sophisticated typewriter: Microsoft Word for their articles, an email client program for their communications, and perhaps whatever browser came installed on their computer to access the Internet. Although there is nothing wrong with this, familiarity with different programs makes one aware that each program has its own logic, its own look and feel. Internet Explorer works one way and has one set of capabilities; Firefox works slightly differently, with a slightly different set of capabilities, and so on. One great advantage I have is that I started using computers when they were mainframes with command lines. My first computer typesetting experience was inserting text commands, which were then run through a program that interpreted them. I learned very quickly that there are as many ways to invoke an action as there are people to write the programs. This knowledge has helped me to grasp the logic of OJS while Kevin still struggles to understand it sometimes.

My brief exposure to UNIX programming means that my eyes do not glaze over quite as fast if someone responds to a query with a term like "cron" or "daemon." However, like the person who knows how to say "hello" and "goodbye" in seven languages, a torrent of programmer language goes right over my head. I understand what "cron" and "daemon" refer to, but have no idea what to do with them. Luckily, with the University of Alberta technical support, I do not have to. It is enormously helpful to be assisted by people who have a greater understanding of the system. It took us several weeks, for instance, to figure out why my copy-editing role was consistently blank. Part of the problem was that the editing page for manuscripts was not showing the information it should, which is a little like saying your computer does not work because you cannot find the on/off switch. That problem must have been universal, because the editing page now includes instructions about what has to happen once a
VOLUME 1 / ISSUE 1 / 2010 


\section{Scholarly and Research} Communication

VOLUME 1 / ISSUE 1 / 2010 manuscript is accepted before the next step can be taken. On-campus support, such as the CJS enjoys, has made the transfer process as painless as it could be. For those lacking institutional or on-campus support, the OJS forums at http://pkp.sfu.ca are helpful to browse and a place to find experienced people who can solve your problem.

The issue that gave us the most angst was subscriptions. Although subscriptions had been declining for some time, they still brought in much-needed revenue. They are also one of the criteria SSHRC uses in evaluating journals as part of its granting process. OJS supports a subscription-based publishing model, and many online journals maintain a fee structure for access, whether based on a fee-per-article or fee-per-issue.

Balancing that consideration was the open access option. Those of us who are baby boomers, or even the children of baby boomers, can be startled by the ability of today's graduate students to manipulate technology. They write computer code, have their own blogs, are denizens (and critics) of the Facebook world, read electronic magazines, and are up to date on a myriad of technological developments. These students will comprise the next generation of scholars; they increasingly expect academic works to be freely available. Barriers to accessing information, such as print media requiring subscriptions and mailing charges, or their online equivalents, will send them elsewhere for more immediately available sources. To them, the "library" is a place online, not a building where they have to search for, and read, information in paper form.

The CJS now routinely receives manuscript submissions from second and third world countries. In an age of widespread Internet access and satellite connections, almost every institution of higher learning or government agency has both Internet access and an Internet presence. In such a context it makes ever less sense to confine knowledge to what can be printed in books or journals and delivered by some variation of mail.

\section{Changing the business model}

Changing the business model from subscription to open access was partly philosophical, partly pragmatic. There are a number of obvious costs in publishing a print journal, almost none of which are within the control of the journal. The costs of paper, printing, binding, transportation, and distribution all have to be factored into the budget. Printers determine their costs based on paper stocks, labour costs, et cetera. Transportation and distribution probably means mail, which in Canada means Canada Post. Taking on any (much less all) of these jobs is neither feasible nor particularly cost-effective. Offloading all of these tasks after accepting a manuscript to a book publisher, such as the University of Toronto Press, relieves an editor of the responsibility, but also the control of subscription databases, timelines, and distribution.

The costs that are controllable - to some extent at least - are those related directly to journal management. For the first five or six years of its existence, the CJS relied on graduate students for editorial assistance, which really amounted to office management. Since then, there have been two editorial assistants: myself for 14 years and another woman for 15 years, both nominally part-time. This provided consistency and familiarity with all aspects of the CJS's affairs. 
Subscriptions can be a critical source of revenue for a print journal, but they also add another informational layer to be tracked and managed. This can quickly become a chicken-and-egg problem. The subscriptions are needed to pay the printing and distribution costs as well as the costs of tracking the subscriptions! Certainly, grants from SSHRC can help cover these costs, as can support from an academic association.

At first blush, online publishing saves an enormous amount of money, which is obviously good news. Open access means that anyone wanting a paper copy can print one from their own computer. Transportation and distribution are non-issues. As open source software, there is no charge for its use. To be sure, it is one of several such software packages, many of which are proprietary or written specifically for one publisher. Free access to a powerful program is a huge saving all by itself.

The crunch for the CJS came with the income provided by subscriptions. An open access journal has neither subscriptions nor subscription revenues. SSHRC does publicly support the open access model and would like to see more journals move in this direction. At the same time, SSHRC has traditionally based its level of journal support at least partially on the number of subscribers. It has not yet clearly committed to a model for measuring the success of open access journals. Citation indexes are one possible criterion. Clearly, a well-regarded open access journal will have even better citation rates than a comparable print journal, simply because more people can access the works. In the end, Kevin's decision was to support the philosophy of open access, for all the reasons noted above, despite some uncertainty about the long-term financial impact. There are, after all, still expenses associated with journal publishing, even online, including salaries, office space, supplies, and the like.

One important point worth noting is that for a new journal, OJS can mean the difference between existence and non-existence. Most funding sources, and certainly SSHRC, require a journal to prove its staying power by publishing for two years before they provide support. Publishing online from the start, in an open access format, is one way to slash costs in those first two years, while developing a reputation as a journal worth reading and contributing to. Using an open source content management system, such as OJS, can help cut costs even more.

\section{Open Journal Systems as content and publication management}

After almost two years of conducting all journal business online, and publishing as open access, we would no longer go back to the way we did things previously. OJS makes it possible for us to assign reviewers, track review progress, email reminders, upload articles - almost anything journal related - anywhere in the world. This is also true for soliciting reviewers. We can reach both a greater pool of scholars and a larger audience of readers. Since academics are a notoriously peripatetic bunch, global access makes the life of journal support staff much easier.

That said, using any unfamiliar computer program brings with it a certain amount of frustration. As more journals enter the online world, content and publication management systems are proliferating and no two are exactly alike in either form or function. It is outside the purview of this article to provide a comparison, but interested readers can check out the British Medical Journal, Cambridge Journal Online, 


\section{Scholarly and Research}

\section{Communication}

VOLUME 1 / ISSUE 1 / 2010
Oxford Journal Online, and others. An Internet search will quickly reveal that most online journals, like most print journals before them, are associated with either a large association or a publishing house. No two are exactly alike.

Revised papers that undergo a second round of reviews are handled quite seamlessly by OJS, once the revision has been submitted in the right place. The program cleverly keeps track of who reviewed the manuscript in the first round and what they recommended, and automatically produces those names (and those names only) for the second review. At the same time, additional reviewers can be solicited, should the original reviewers be unavailable for the second round. However, the process of getting to the second round is not yet as transparent as it might be. Once understood, the logic is reasonable, but as alluded to earlier, it is far from intuitive.

Page proofs can be sent to authors from within the program, which also has a panel for keeping track of the editing and proofing processes prior to publishing. Issues can be set up as far in advance as there are papers to fill them, which allows a much clearer projection of a given volume's content and publication date.

Everyone who works with OJS likely develops a wish list of "improvements" they would like. A huge advantage of OJS is that such a wish list can be communicated to the programmers with a reasonable expectation that it will be carefully considered and possibly acted on in the future. Although this is probably true of other, even all, content management systems, the OJS forums make communication and response more immediate and direct.

One item on our wish list is a way to number submissions that is journal specific, rather than system-wide. Since the University of Alberta supports several OJS journals, numbering is shared across them, taking our submissions from Article 511 to Article 4522 in the short space of one year. Where we used to be able to simply take the largest submission number for a year and subtract the lowest submission number to get the total number of submissions to the CJS, now they have to be counted. This is not quite as onerous as it sounds, since each section provides a running total of the number of articles. However, the process does not prevent counting articles more than once if they were submitted separately for review, re-review, and publication.

Another item on my wish list was mentioned earlier in this article. The roles in OJS were set up to compartmentalize and account for all the various jobs within scholarly journal publishing. Most academic journals, however, including the CJS, have one editorial assistant plus an editor - and many operate with one editor and a graduate student who changes from year to year. An ability to blend the roles more seamlessly would be very helpful.

A huge additional item on my wish list is documentation. OJS is open source programming, maintained by volunteers with paying jobs that require at least some of their attention. Moreover, it is a peculiar feature of computer program documentation that the people who know the software best are often the worst people to write it up. To be useful to beginners, documentation needs to start from the assumption that the potential user knows nothing about OJS and little about computer programs in general. 
The documentation for OJS has not kept pace with the various updates, making the already inadequate instructional booklets increasingly irrelevant. This will not change until those of us who can identify major frustrations with the system choose to step up and join the volunteers.

Adequate documentation of updates might help avoid situations like the one we dealt with recently. One of the recent "improvements" to the system was the introduction of automated reminders for reviewers. For some journals, unfortunately, these do not appear to have worked at all. For the CJS, they worked in a distressingly random manner, and not always appropriately. Imagine the surprise of the reviewers who found themselves reminded to submit a review for a paper that had already appeared in print! Such glitches can produce comical moments, but more seriously can harm a journal's professional reputation. Fortunately, such features can be turned off at the local server level, but not before we had to deal with a number of perturbed reviewers.

Computers (and computer programs) are extremely linear, no matter how "intuitive" they may appear on the surface. Many of the frustrations we experience with OJS prove to be a case of trying to do things in the wrong order. Click "this," then "that," even if "this" does not seem to apply. Otherwise, "that" will remain annoyingly inaccessible, and totally unresponsive to muttered (or shouted) imprecations. Authors and reviewers are most often caught by this - for a while, reviews remained open long after they had been submitted if the reviewer did not use the drop-down list of possible recommendations. Another source of unnecessary automatic reminder emails, as it turned out.

The multilanguage support is a boon to us since we publish in both French and English. One pitfall is that the translations of the various pre-set communications can leave something to be desired to the ear of a native speaker. Since these are easily altered by the Journal Manager, solving this problem becomes a matter of ensuring accurate and, with luck, elegant translations where needed. But beware! This level of customization can disappear with an upgrade to the system and there will be no warning unless you check, or someone draws your attention to some finer point of translation.

In the end, these are all quibbles, not deal breakers. OJS is free to use, so there is no financial investment. A willingness to ask questions and play with the program (you cannot actually break it, after all) will likely convince you that, if open access is the way you want to take your journal, OJS is a good way to do it. In fact, OJS can be used for as much or as little as suits your needs. If you want to standardize your computer records for submissions and reviews by using the online submission and review process, you can do that and still produce a print journal at the end. If you want to produce your journal online but need some level of subscription income to cover costs, OJS will accommodate that as well.

For us, the decision hinged on a number of factors: institutional support for OJS and people on campus to whom we could take our questions and problems; long-term staff (even though half-time) with the patience and ability to figure out how the program works and how to make it work better; a commitment (although it felt a little
VOLUME 1 / ISSUE $1 / 2010$ 
Scholarly and Research

\section{Communication}

VOLUME 1 / ISSUE 1 / 2010 like jumping out of a plane without being sure of one's parachute) to the philosophy of open access and a willingness to make the effort to turn it into a reality; and the realization that the loss of subscription funds has been more than offset by the lack of printing costs.

Last, but not least, one of the more pleasant and unanticipated consequences of our taking this leap is that both Kevin and I have found ourselves in the role of "mentor" to various colleagues considering the same decision with the same trepidation. We hope our article continues this process of guiding colleagues who are grappling with the ongoing changes in the world of academic publishing.

\section{Notes}

1. The Social Sciences and Humanities Research Council and its companion, the Natural Sciences and Engineering Research Council of Canada, provide funding on a competition basis for many Canadian scholarly publications. Referred to as competitive grants, the amounts depend on various rubrics such as circulation, subscription rates, and so on.

2. In fact, I have been Assistant to the Editor twice: the first time from 1978 to 1990 , the second since 2007 .

3. Textform, for those with long memories. 